\title{
THE NORMAL ELECTROCARDIOGRAM
}

\author{
BY
}

\author{
E. NOBLE CHAMBERLAIN AND J. DUNCAN HAY
}

From the Heart Department, the Royal Infirmary, Liverpool

Received November 18, 1938

It is necessary at intervals to revise our standards of the normal in all sciences. This is particularly desirable in electrocardiography, where important advances are made yearly in its application to the diagnosis of cardiac disease. It is very easy for minor changes in the electrocardiogram to loom too largely in the diagnostic picture ; but if the wide limits of normal variation are realized, some of the pitfalls will be avoided.

The most important early work on the normal electrocardiogram is that of Lewis (1912), who constructed tables giving the amplitude of various waves and the length of the various intervals usually measured in the human electrocardiogram. His work was carried out on fifty healthy subjects and the description of the characteristics of each wave forms the basis of our presentday interpretation of the electrocardiogram.

Another and more recent important contribution was the study of the electrocardiogram in late middle life by Jensen, Smith, and Cartwright (1931-2). Their investigation consisted of the analysis of fifty cases between the ages of fifty and sixty-five to determine if there were " any changes which, though not common in the tracings of younger people, could nevertheless be considered physiologic at this stage of life". Their conclusions are summarized below.

(1) The following findings were not considered pathological :

(a) Diphasic or iso-electric $\mathrm{P}$ waves in lead $\mathrm{I}$, or inverted $\mathrm{P}$ waves in lead III if they become upright on deep inspiration.

(b) Slurring of the QRS complexes, especially in lead III, and slight to moderate notching of $\mathrm{R}$, with the QRS interval below $0 \cdot 10 \mathrm{sec}$.

(c) " Transverse heart."

(d) Isolated left ventricular preponderance.

(e) Moderate inversion of T in lead III.

(2) The following findings, on the other hand, were not present in their series and were therefore to be looked upon with suspicion :

(a) Indeterminate or inverted P waves in leads I or II.

(b) Inverted P waves in lead III if they did not become upright on deep inspiration.

(c) P-R interval exceeding $0 \cdot 20$ of a second, QRS interval exceeding $0 \cdot 10$, or S-T exceeding $\mathbf{0 . 3 4 - 0 . 3 6}$ of a second (the upper limit seems slightly uncertain). 
They conclude that there did not seem to be any characteristic changes in the electrocardiogram with increasing age. The writers of the present paper felt that a larger series of cases might indicate whether some of the minor defects sometimes taken as pathological could, in reality, be physiological. At the same time it was hoped to make a more extensive study of the variation of the electrocardiogram with age.

\section{Clinical Material}

Each subject was, as far as possible, subjected to such a clinical examination as to exclude the likelihood of any cardiovascular disease or of any disease likely to affect the cardiovascular system temporarily. A large number were nurses and medical students apparently in perfect health. Others were patients in hospital for trivial surgical causes, and in them a generous interval was allowed after any operative interference had been undertaken. All cases that had any symptoms suggestive of cardiac involvement, any rise of blood pressure, any enlargement of the heart, or any murmurs which were not clearly functional were rigorously excluded. Further, no one who had suffered from rheumatic fever, chorea, repeated tonsillitis, syphilis, or other ætiological factors of heart disease was included. The Wassermann reaction was performed in each and the subject excluded if it was positive.

In all, 302 subjects were examined of whom more than half were in the third and fourth decades, a period of life when the cardiovascular system is likely to be intact. Measurements were made of the amplitude of $\mathrm{P}, \mathrm{Q}, \mathrm{R}, \mathrm{S}$, and $T$ in all three leads. The time intervals P-R, QRS, and S-T were measured only in lead II. Details of these figures are to be seen in the accompanying tables.

\section{RESULTS}

The results may be summarized as regards the various waves, axis deviation, and the time intervals.

$P$ Wave.-In a number of instances $P 1$ was flat or scarcely perceptible. P 2 was usually well developed, and P 3 variable. Inverted $P$ waves of a welldefined character were only observed in lead III. Four examples were noted in the second, third, and fifth decades. Occasional splitting of the summit of the $P$ wave was noticed, not unlike that found more frequently in mitral stenosis.
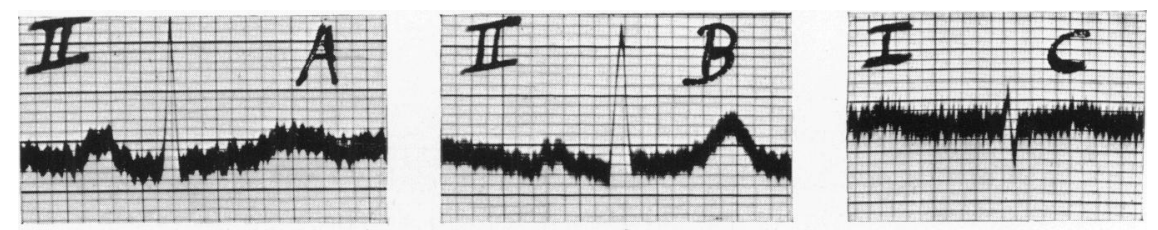

FIG. 1.-Types of $\mathbf{P}$ wave : (A) $\mathbf{P}$ with broad summit ; (B) Bifurcation of $\mathbf{P}$; (C) Absent $\mathbf{P}$ in lead $\mathbf{I}$.

$Q$ Wave.-Q was absent in a large number of cases and was never more than $4.5 \mathrm{~mm}$. in amplitude. 

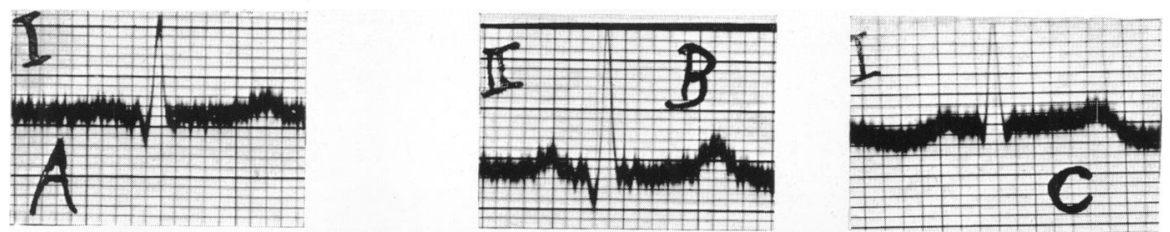

FIG. 2.-Types of $\mathrm{Q}$ wave : (A) and (B) Well-defined $\mathrm{Q}$ waves ; (C) $\mathrm{Q}$ scarcely perceptible.

$R$ Wave.-The limits of variation in this wave were extreme. In lead $I$ the wave might be as little as $1.5 \mathrm{~mm}$. or as much as $18.6 \mathrm{~mm}$. ; in lead II as little as $3.6 \mathrm{~mm}$. or as much as $23.6 \mathrm{~mm}$. ; whilst in lead III it varied between 0.5 and $20.5 \mathrm{~mm}$. Slight notching of $\mathrm{R}$ was fairly common in all leads, especially in the descending limb. Splitting and low voltage of the QRS complex in lead III was very common.
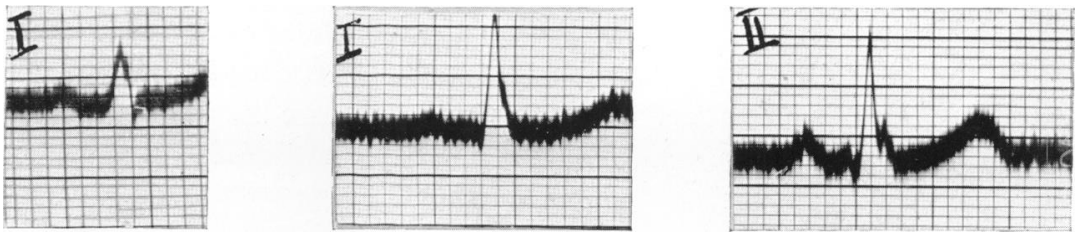

FIG. 3.-Types of $R$ wave : Three examples of slight degrees of notching of $R$ in lead $I$.

$S$ Wave.-This varied from 0.0 to $11.5 \mathrm{~mm}$. and Fig. 4 shows well-defined waves. In many cases the descending limb of $\mathrm{R}$ did not come straight down to the iso-electric line, but sloped gradually into it (Fig. 5).
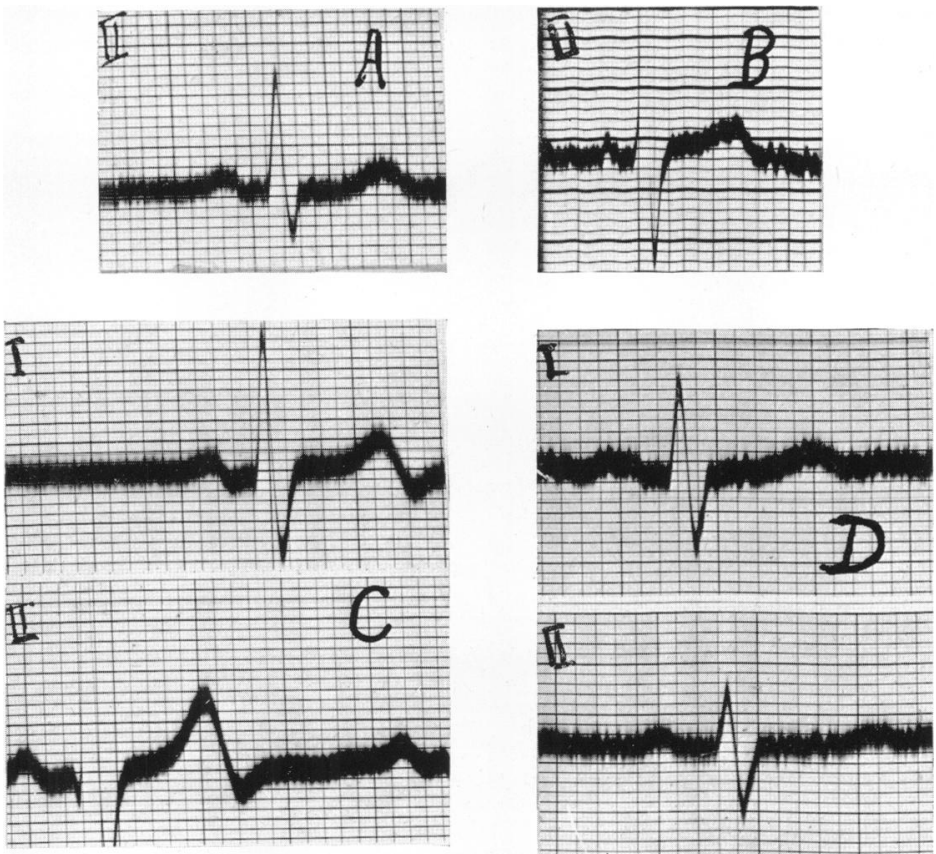

Fig. 4.-Types of $S$ wave : (A) and (B) S well defined, prominent in $B$; (C) and (D) $S$ prominent leads I and II. 

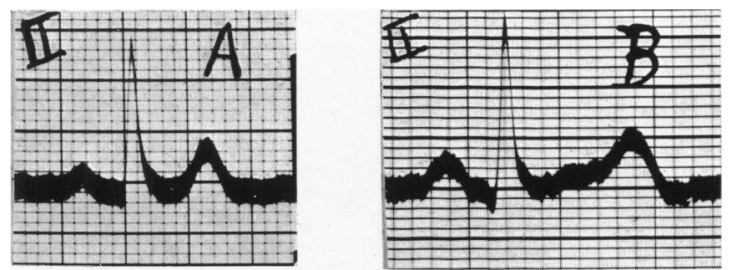

FIG. 5.-Types of $\mathrm{S}$ wave : (A) and (B) $\mathrm{S}$ indeterminate, slurring into R-T segment.

$S$-T Interval.-The S-T interval was studied with particular care in view of its great importance in relation to coronary thrombosis. Slurring of the $\mathrm{R}$ wave into the S-T segment was not uncommon (Fig. 2) especially when the portable electrocardiograph was used, and must also be distinguished from genuine S-T deviation. Out of 302 cases only 5 records showed the slightest S-T deviation. Occasionally there was a false impression of S-T deviation due to the fact that the P-Q interval sank below the iso-electric level. The degree of S-T deviation observed in the cases mentioned did not amount to more than $1.5 \mathrm{~mm}$. (Fig. 6).
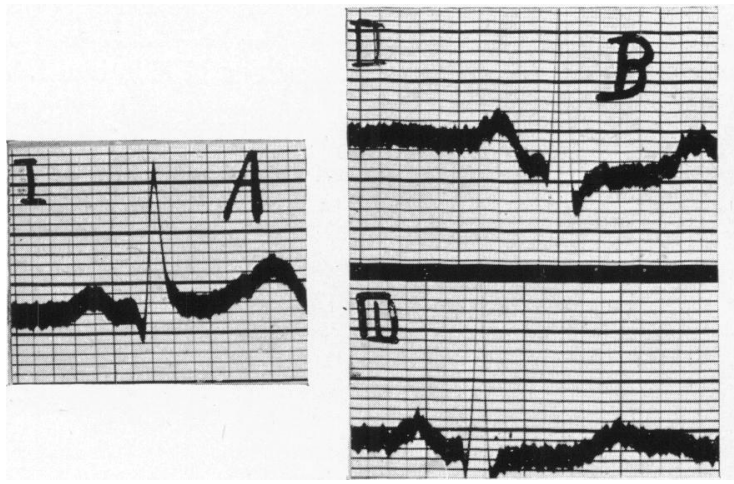

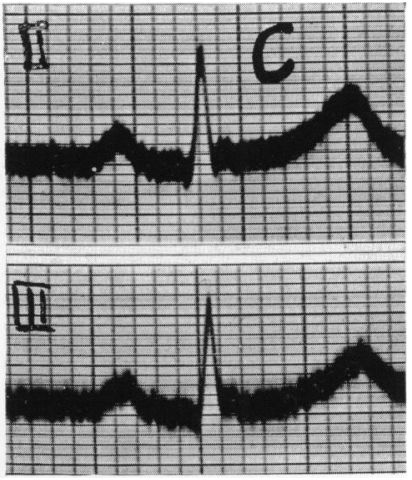
FIG. 6.-Types of S-T interval : (A) Slight S-T deviation ; (B) Slight S-T depression in
leads II and III ; (C) False impression of S-T deviation owing to depression of P-Q interval.

The configuration of the S-T interval varied greatly in different normal subjects. In some there was a long iso-electric period often lasting 0.16 of a second, while in others it was shorter or absent (Fig. 7). In some cases where there was no iso-electric period, the $\mathrm{T}$ wave took origin in a steep fashion from a deep $\mathrm{S}$ wave (Fig. 8).

QRS Complex.-The QRS complex showed great variation in lead III. This fact is well established, and it is rare to find any pathological importance attached to it. A more careful study was made of the variation in leads I and II. Out of the 302 cases examined, only 15 showed any notching of the QRS in these leads (Fig. 9), and another 11 showed low voltage without notching (Fig. 10). Whenever notching was prominent some degree of low voltage was usually present.

Axis Deviation.--Right ventricular preponderance was noted in 3 cases in a pronounced form and to a slight degree in 15 others. Left ventricular 

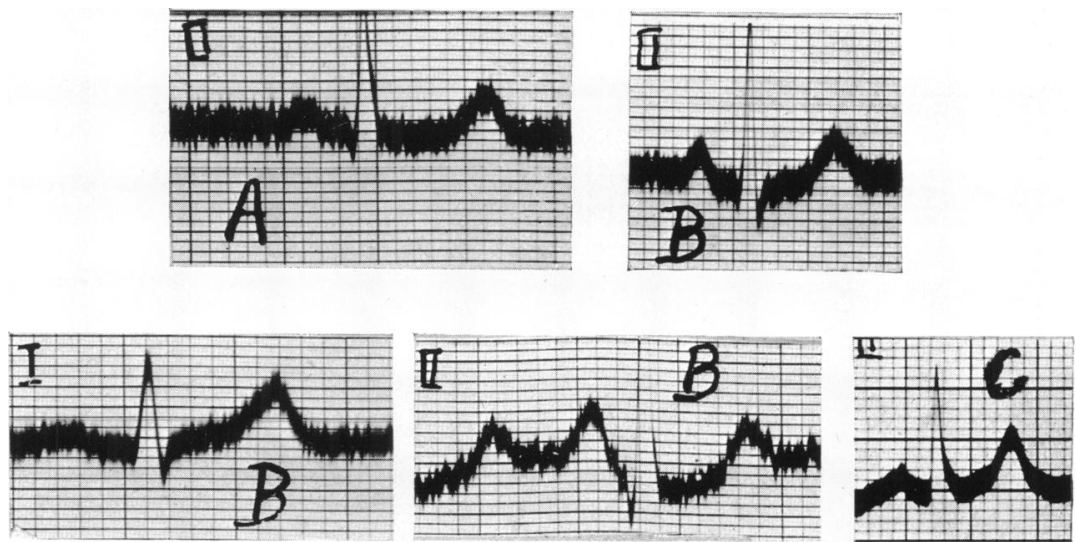

Fig. 7.-Type of S-T interval in leads I and II : (A) Long iso-electric period before T wave ; (B) Short iso-electric periods ; (C) No iso-electric period.
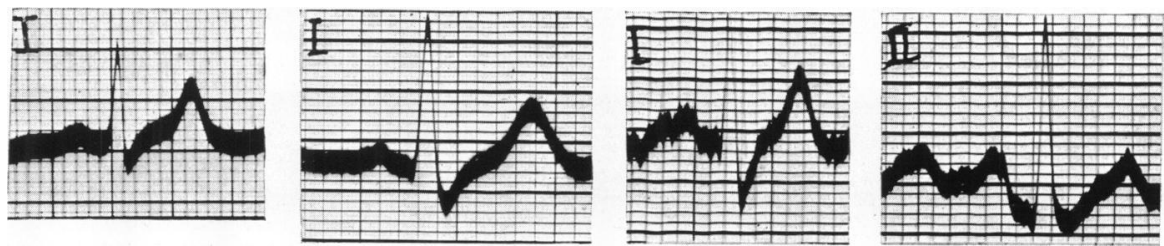

Fig. 8.-Types of S-T interval in leads I and II : Four cases showing no iso-electric period, $\mathrm{T}$ taking origin from a deep $\mathrm{S}$ wave.
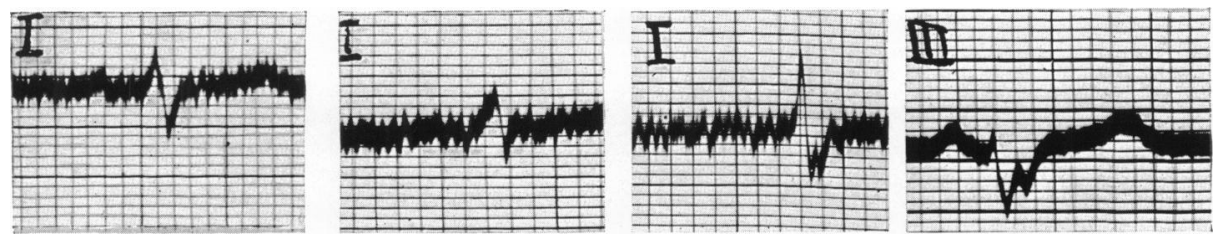

Fig. 9.-Types of QRS ; Notching: The first three cases show various types of notching of $Q R S$ in lead I; the fourth shows pronounced notching of QRS in lead III.
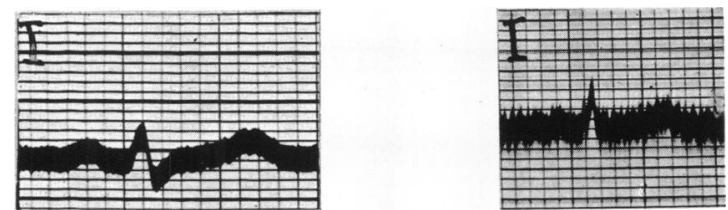

FIG. 10.-Types of QRS ; Low voltage : Two examples of low voltage in lead I. 
preponderance occurred in a moderate or pronounced form 26 times, i.e., in 8 per cent. of all cases; and slighter degrees were present in another 24 cases. In the third decade where 136 cases were available, there were 9 with slight and 7 with pronounced left ventricular preponderance, i.e. a total of 12 per cent. It would appear, therefore, that left axis deviation is a comparatively common finding in the normal electrocardiogram. It is notable that minor degrees of ventricular preponderance vary from complex to complex, probably due to respiratory variations.

$T$ Wave.-The $\mathrm{T}$ wave varied greatly in amplitude, in the case of positive waves from 0.0 to $12.5 \mathrm{~mm}$. The commonness of inversion of $\mathrm{T} 3$ is universally recognized, but it is interesting to note that it occurred in as many as 87 out of 302 cases. In view of the attention paid to the various shapes of inverted $\mathrm{T}$ (e.g. in digitalis poisoning and coronary thrombosis) it is also important to recognize that considerable variation may be found in the normal from rounded waves to quite sharp ones (Fig. 11). In no case was inversion of $\mathrm{T}$ observed in lead I (although $\mathrm{T}$ was often flat), but inversion in leads II and III together was present in four cases.
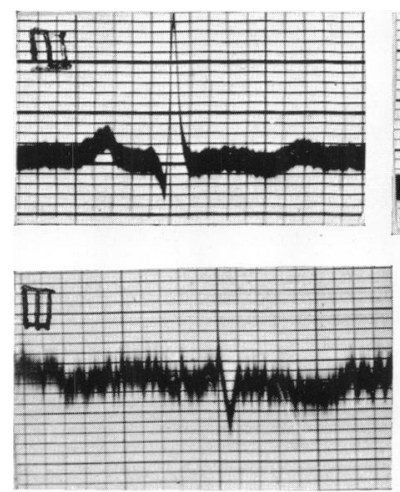
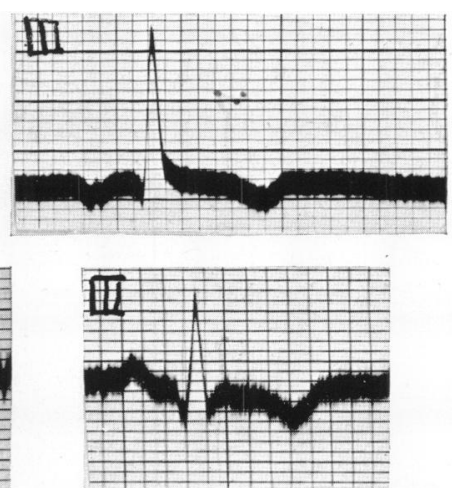
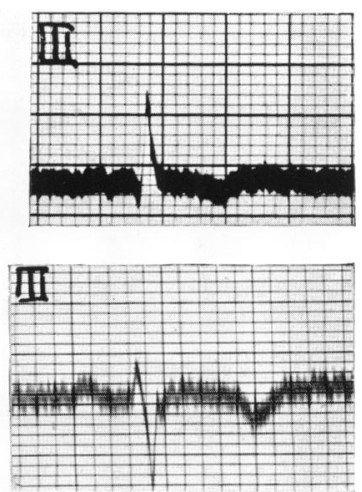

FIG. 11.-Types of negative $\mathrm{T}$ in lead III.

Time Intervals : $P-R$.- This interval varied from $0 \cdot 12$ to 0.22 of a second. The reading of 0.22 occurred in four subjects, three of whom were young people (Fig. 12). This is notable in view of the generally accepted view that the P-R interval should not exceed $0 \cdot 20$ of a second.

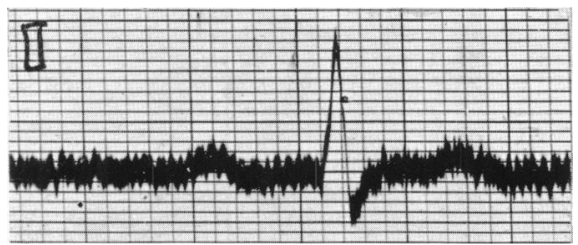

Fig. 12.-Prolonged P-R.: Four examples of a P-R interval of 0.22 of a second occurred in this series of 302 normal persons.

$Q R S$.- The minimum was $0 \cdot 04$ seconds and the maximum $0 \cdot 10$, figures not varying from those usually accepted as normal. 
$S$-T.-The minimum was $0 \cdot 20$ of a second, though such a low figure was only observed in a child. The maximum was 0.36 of a second.

\section{Discussion OF RESULTS}

Table I has been constructed to compare the average measurements of the electrocardiogram in the second, third, and fourth decades with those in the fifth, sixth, and seventh. As Lewis's work was principally on young persons, it will be more satisfactory to compare his results with those of the second, third, and fourth decades.

A comparison indicates that, on the whole, there are no great differences between his figures and those of the present series, though in the latter the amplitude of most waves appears to be rather greater.

The $P$ wave showed an average amplitude of 0.8 and $1.9 \mathrm{~mm}$. in leads $I$ and II, compared with figures of 0.52 and $1.16 \mathrm{~mm}$. in Lewis's series. In both series $P$ averaged $0.8 \mathrm{~mm}$. in lead III.

The measurements of $\mathrm{Q}$ were almost identical in the two series. The measurements of $\mathrm{R}$ were uniformly greater in all three leads in the present series. $\mathrm{S}$ showed no appreciable difference, and $\mathrm{T}$ was only slightly greater in leads I and II.

TABLE I

Comparison of Average Measurements in Normal Subjects

\begin{tabular}{|c|c|c|c|c|c|c|c|}
\hline \multicolumn{3}{|c|}{ Decade } & $\mathbf{P}$ & Q & $\mathbf{R}$ & $\mathbf{S}$ & $\mathbf{T}$ \\
\hline \multicolumn{8}{|c|}{ Lead I } \\
\hline $\begin{array}{l}\text { 2nd, 3rd, and 4th } \\
5 \text { th, 6th, and 7th }\end{array}$ & $\begin{array}{l}\cdots \\
\cdots\end{array}$ & \begin{tabular}{l|l}
$\ldots$ \\
$\ldots$
\end{tabular} & $\begin{array}{l}0 \cdot 8 \\
0 \cdot 7\end{array}$ & $\begin{array}{l}0 \cdot 5 \\
0 \cdot 7\end{array}$ & $\begin{array}{l}8 \cdot 1 \\
7 \cdot 9\end{array}$ & $\begin{array}{l}2 \cdot 0 \\
1 \cdot 5\end{array}$ & $\begin{array}{l}2 \cdot 8 \\
2 \cdot 2\end{array}$ \\
\hline \multicolumn{8}{|c|}{ Lead II } \\
\hline $\begin{array}{l}\text { 2nd, 3rd, and 4th } \\
5 \text { th, 6th, and 7th }\end{array}$ & $\begin{array}{l}\cdots \\
\cdots\end{array}$ & $\begin{array}{l}. . \\
.\end{array}$ & $\begin{array}{l}1.9 \\
1.8\end{array}$ & $\begin{array}{l}0 \cdot 8 \\
1 \cdot 1\end{array}$ & $\begin{array}{l}14 \cdot 0 \\
11 \cdot 4\end{array}$ & $\begin{array}{l}3 \cdot 0 \\
2 \cdot 4\end{array}$ & $\begin{array}{l}3 \cdot 2 \\
2 \cdot 8\end{array}$ \\
\hline \multicolumn{8}{|c|}{ Lead III } \\
\hline $\begin{array}{l}\text { 2nd, 3rd, and 4th } \\
5 \text { th, 6th, and 7th }\end{array}$ & $\begin{array}{l}\ldots \\
\ldots\end{array}$ & $\begin{array}{l}\cdots \\
\cdots\end{array}$ & $\begin{array}{l}0 \cdot 8 \\
0 \cdot 8\end{array}$ & $\begin{array}{l}0.6 \\
0.7\end{array}$ & $\begin{array}{l}8 \cdot 8 \\
5 \cdot 8\end{array}$ & $\begin{array}{l}1 \cdot 5 \\
2 \cdot 1\end{array}$ & $\begin{array}{l}0 \cdot 3 \\
0.0\end{array}$ \\
\hline
\end{tabular}

\section{Age VARIATIONS}

The changes with age were less than might have been anticipated. There were no significant changes in the $P$ waves in any leads.

The $Q$ waves showed a slight increase in all leads in the aggregate of the fifth, sixth, and seventh decades. 
The $\mathrm{R}$ waves in leads II and III appeared to be maximum in the third and fourth decades, but the amount of variation was not enough to be of any importance. On the whole, however, the later decades showed a rather smaller amplitude in the $\mathrm{R}$ waves than the earlier ones.

The $\mathrm{S}$ waves did not appear to be materially altered.

The $\mathrm{T}$ wave in lead $\mathrm{I}$ seemed to be larger in the earlier decades of life. In leads II and III it was also rather larger, though comparison of the average figures for the second, third, and fourth decades with the fifth, sixth, and seventh decades did not show any great difference.

Table II shows that there was no appreciable difference in the average P-R interval or in the duration of QRS or of S-T between the three earlier and the three later decades.

TABLE II

Average Duration of P-R, QRS, and S-T in Lead II in Earlier and Later Decades

\begin{tabular}{|c|c|c|c|c|}
\hline & & $\mathbf{P}-\mathbf{R}$ & QRS & S-T \\
\hline 2nd, 3rd, and 4th decades & .. & $1 \cdot 8$ & 0.06 & $0 \cdot 28$ \\
\hline 5 th, 6th, and 7 th decades. & .. & $1 \cdot 7$ & 0.06 & $0 \cdot 28$ \\
\hline
\end{tabular}

Left ventricular preponderance, as might be expected, was greater in the later decades of life. Out of 136 cases in the third decade it occurred in a pronounced form in 5 per cent., whilst out of 88 cases in the fifth, sixth, and seventh decades it occurred in 16 per cent. Those cases which showed inversion of $\mathrm{T}$ in leads II and III occurred in the third and fourth decades. The incidence of negative $T$ waves in lead III was, curiously enough, greater in the first decade ( 6 cases), though the total number available in this decade was too small ( 8 cases) to draw any definite conclusions. Apart from this anomaly, the incidence of a negative $\mathrm{T}$ wave in lead III appeared to be roughly similar in all decades of life.

\section{SUMMARY}

1. To determine the limits of physiological variation in the electrocardiogram and any changes that might occur with age, 302 normal subjects have been investigated. Each was subjected to a rigorous examination, including blood pressure readings and Wassermann reaction. The following points are deemed worthy of emphasis.

2. The $P$ wave was often flat or scarcely perceptible in lead I and occasionally had a split or broad summit. A few examples of inversion of $\mathbf{P} 3$ were seen.

3. The $R$ wave varied within wide limits in its amplitude and slight notching of the descending limb was not uncommon. 
4. The $\mathrm{S}$ wave, although usually well defined, may slope gradually into the R-T segment.

5. True S-T deviation was so rare and so minute that it must be regarded with great suspicion, but peculiarities in the formation of the S-T interval were very common and must not be confused with genuine S-T deviation.

6. Slight degrees of notching and of low voltage in the QRS complex in leads I and II were not uncommon. The types of record found can be seen better by inspection of the illustrations than by description.

7. Right axis deviation in a pronounced form was uncommon even in young persons, whilst left axis deviation occurred quite frequently at all ages, increasingly so in the later decades where it was found in one sixth of all cases.

8. Inversion of $T$ was never found in lead $I$, but inversion of $T$ in both leads II and III was present in four cases. The former must be considered as pathological whenever it occurs, and the latter as suspicious. Inversion of $T$ in lead III only was present in 29 per cent. of the total 302 cases and considerable variation in the shape of the wave was recognized.

9. The only unusual finding as regards time intervals was the occurrence of a few cases where the P-R interval was 0.22 of a second.

10. Age variations were slight, the most important being an increase in the left axis deviation in the later decades of life.

We wish to thank Dr. J. L. Chisnall for his help in the statistical part of this work and Mr. E. Caldwell for his careful work with the electrocardiograms.

\section{REFERENCES}

Jensen, J., Smith, M., and Cartwright, E. D. (1931-2). Amer. Heart J., 7, 718. Lewis, T., and Gilder, M. D. D. (1912). Phil. Trans. Roy. Soc., Lond., 202, 351.

TABLE III

Measurements of P, Q, R, S, and T Waves in Normal Subjects

$\begin{array}{lllll}P & Q & R & S & T\end{array}$

Lead I

First decade ; 8 cases

Average

Maximum $\quad \cdots \quad \cdots \quad 0.9$

$\begin{array}{llll}\text { Minimum } & . & \ldots & 0.0\end{array}$

Lead II

$\begin{array}{llll}\text { Average } & \ldots & \ldots & 1 \cdot 5 \\ \text { Maximum } & \cdots & 3.0\end{array}$

Maximum $\quad \ldots \quad \ldots .30$

Minimum $\quad \ldots \quad \ldots .5$

Lead III

Average

Maximum

Minimum $\begin{array}{llr}\ldots & . . & -0.2 \\ . & . . & 1.5 \\ . & . . & -0.5\end{array}$
$1 \cdot 0$

3.6

0.6

$0 \cdot 5$

$4 \cdot 0$

0.0
$8 \cdot 2$
$11 \cdot 6$

$5 \cdot 6$

$12 \cdot 5$
$19 \cdot 5$

$7 \cdot 5$

0.4
3.5

$3 \cdot 5$

0.0
$1 \cdot 7$

$7 \cdot 6$
0.0

$3 \cdot 1$

$4 \cdot 6$

$4 \cdot 6$
1.6

$\begin{array}{rr}1.7 & 2.2 \\ 2.5 & 5.5 \\ 0.5 & 0.5 \\ & \\ & \\ 0.8 & -0.5 \\ 1.5 & 1.5 \\ 0.5 & -1.5\end{array}$


TABLE III-continued

Measurements of P, Q, R, S, and T Waves in Normal Subjects

$\begin{array}{lllll}\mathbf{P} & \mathbf{Q} & \mathbf{R} & \mathbf{S} & \mathbf{T}\end{array}$

Lead I Second decade ; 25 cases

\begin{tabular}{lllllrlr} 
Average & & \multicolumn{7}{c}{. } &. & 1.0 & 0.9 & 8.8 & 2.3 & 3.3 \\
Maximum & $\ldots$ & $\ldots$ & 2.5 & 3.5 & 18.6 & 8.0 & 4.5 \\
Minimum &.. & $\ldots$ & 0.0 & 0.0 & 2.0 & 0.0 & 1.5
\end{tabular}

Lead II

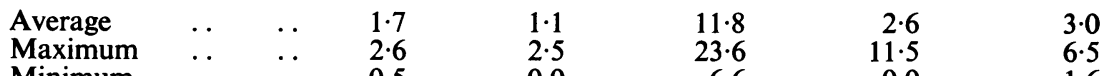

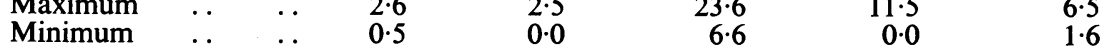

Lead III

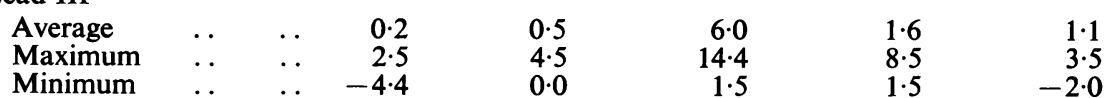

Lead I

Third decade ; 136 cases

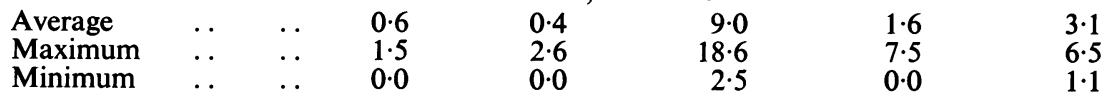

Lead II

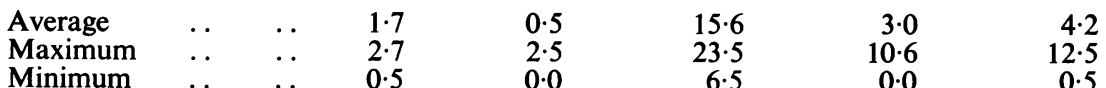

Minimum 0.5

Lead III

$\begin{array}{lllllrrr}\text { Average } & . & \ldots & 0.7 & 0.5 & 9.3 & 1.5 & -0.3 \\ \text { Maximum } & & & 2.5 & 3.6 & 20.5 & 8.5 & 6.5\end{array}$

$\begin{array}{lrrrrrr}\text { Minimum } & \ldots & \ldots & 2.5 & 3.6 & 20.5 & 8.5 \\ \end{array}$

Lead I Fourth decade ; 36 cases

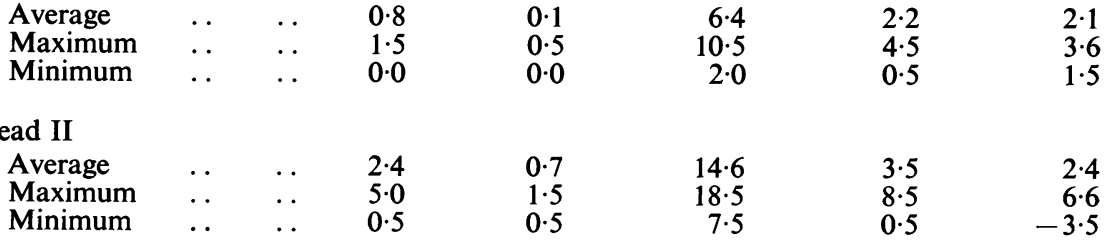

Lead III

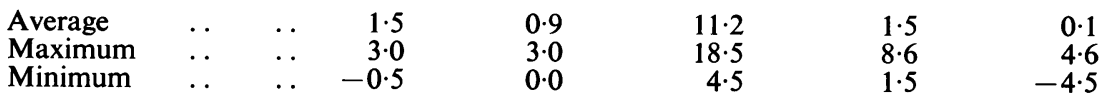

Lead I Fifth decade ; 42 cases

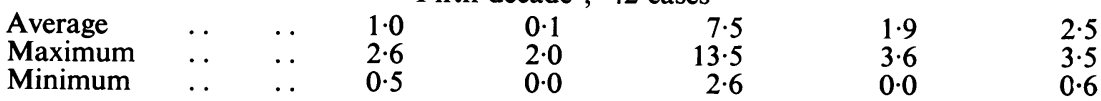

Lead II

\begin{tabular}{|c|c|c|c|c|c|c|c|}
\hline $\begin{array}{l}\text { Average } \\
\text { Maximum } \\
\text { Minimum }\end{array}$ & $\begin{array}{l}\cdots \\
\cdots \\
\cdots\end{array}$ & $\begin{array}{l}\cdots \\
\cdots\end{array}$ & $\begin{array}{l}2 \cdot 0 \\
2 \cdot 6 \\
0 \cdot 0\end{array}$ & $\begin{array}{l}0 \cdot 6 \\
2 \cdot 6 \\
0 \cdot 0\end{array}$ & $\begin{array}{r}12 \cdot 4 \\
16 \cdot 4 \\
4 \cdot 5\end{array}$ & $\begin{array}{l}3.0 \\
5.0 \\
0.0\end{array}$ & $\begin{array}{l}2 \cdot 7 \\
4 \cdot 6 \\
0.6\end{array}$ \\
\hline ead III & & & & & & & \\
\hline $\begin{array}{l}\text { Average } \\
\text { Maximum } \\
\text { Minimum }\end{array}$ & $\begin{array}{l}\cdots \\
\cdots \\
\cdots\end{array}$ & $\begin{array}{l}\cdots \\
\cdots\end{array}$ & $\begin{array}{r}1.0 \\
2.6 \\
-4.0\end{array}$ & $\begin{array}{l}0.4 \\
4.0 \\
0.0\end{array}$ & $\begin{array}{r}6 \cdot 8 \\
13 \cdot 4 \\
1.6\end{array}$ & $\begin{array}{l}2 \cdot 2 \\
4 \cdot 5 \\
0 \cdot 0\end{array}$ & $\begin{array}{r}0.0 \\
2.5 \\
-5.0\end{array}$ \\
\hline
\end{tabular}


TABLE III-continued

Measurements of $P, Q, R, S$, and T Waves in Normal Subjects
$P$
Q
$\mathbf{R}$
$\mathbf{S}$
$\mathbf{T}$

Lead I

Sixth decade ; 33 cases

\begin{tabular}{|c|c|c|c|c|c|c|c|}
\hline $\begin{array}{l}\text { Average } \\
\text { Maximum } \\
\text { Minimum }\end{array}$ & $\begin{array}{l}. \\
\therefore\end{array}$ & $\begin{array}{l}\ldots \\
\because .\end{array}$ & $\begin{array}{l}0.6 \\
1.5 \\
0.0\end{array}$ & $\begin{array}{l}0.7 \\
2.5 \\
0.0\end{array}$ & $\begin{array}{r}7.8 \\
13 \cdot 6 \\
1.5\end{array}$ & $\begin{array}{l}1 \cdot 2 \\
6 \cdot 5 \\
1 \cdot 5\end{array}$ & $\begin{array}{l}2.0 \\
3.5 \\
0.0\end{array}$ \\
\hline Lead II & & & & & & & \\
\hline $\begin{array}{l}\text { Average } \\
\text { Maximum } \\
\text { Minimum }\end{array}$ & $\begin{array}{l}. \\
\cdots \\
. .\end{array}$ & $\begin{array}{l}\ldots \\
\cdots\end{array}$ & $\begin{array}{l}1.9 \\
3.5 \\
0.5\end{array}$ & $\begin{array}{l}1 \cdot 3 \\
4 \cdot 5 \\
0 \cdot 0\end{array}$ & $\begin{array}{r}11 \cdot 3 \\
16 \cdot 5 \\
5 \cdot 5\end{array}$ & $\begin{array}{l}2 \cdot 3 \\
9 \cdot 5 \\
1.5\end{array}$ & $\begin{array}{l}3.0 \\
7.5 \\
0.5\end{array}$ \\
\hline _ead III & & & & & & & \\
\hline $\begin{array}{l}\text { Average } \\
\text { Maximum } \\
\text { Minimum }\end{array}$ & $\begin{array}{l}\because \\
\therefore\end{array}$ & $\begin{array}{l}\because \\
\therefore\end{array}$ & $\begin{array}{r}1.4 \\
3.0 \\
-1.5\end{array}$ & $\begin{array}{l}1 \cdot 2 \\
4 \cdot 5 \\
0 \cdot 0\end{array}$ & $\begin{array}{r}5.9 \\
14.6 \\
0.0\end{array}$ & $\begin{array}{r}2 \cdot 2 \\
10 \cdot 5 \\
1 \cdot 5\end{array}$ & \\
\hline
\end{tabular}

Lead I

Seventh decade ; 13 cases

$\begin{array}{lllllrll}\text { Average } & . & . . & 0.9 & 1.2 & 8.4 & 1.4 & 2.1 \\ \text { Maximum } & . & . & 1.5 & 2.5 & 13.6 & 2.5 & 3.5 \\ \text { Minimum } & . & . . & 0.0 & 0.0 & 2.5 & 0.5 & 0.5\end{array}$

Lead II

$\begin{array}{lllrrrrr}\text { Average } & . & . . & 1.5 & 1.5 & 10.4 & 2.0 & 2.8 \\ \text { Maximum } & . & . & 2.5 & 3.0 & 17.6 & 4.5 & 5.5 \\ \text { Minimum } & . & . & 0.5 & 0.0 & 3.6 & 0.0 & 1.5\end{array}$

Lead III

$\begin{array}{llrrrrrr}\text { Average } & . & . . & 0.2 & 0.5 & 4.6 & 2.0 & -0.7 \\ \text { Maximum } & \ldots & . . & 1.5 & 2.5 & 18.6 & 7.5 & 3.5 \\ \text { Minimum } & . & . . & -1.5 & 0.0 & 0.5 & 0.0 & -4.5\end{array}$


TABLE IV

Measurements of P-R, QRS, and S-T Intervals in Seconds, in Normal Subjects (LEAD II ONLY)$$
\text { P-R }
$$

QRS

S-T

First decade

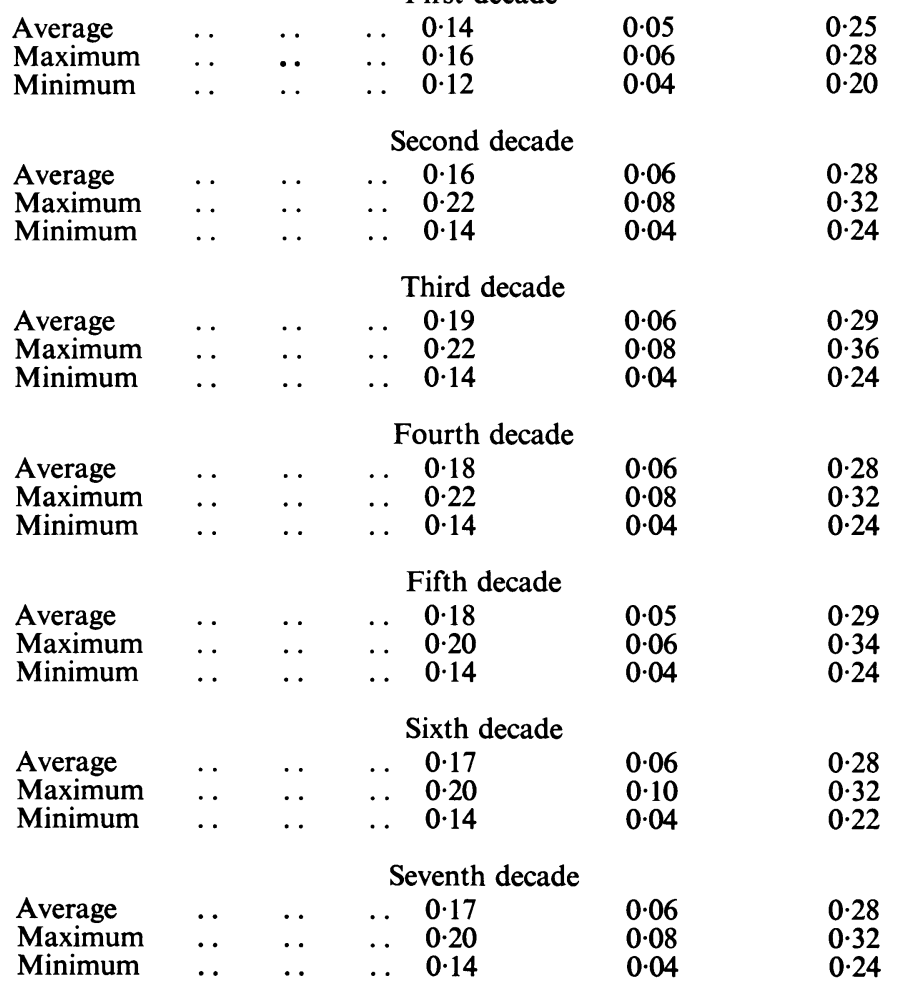

